\title{
DOCÊNCIA E GESTÃO DEMOCRÁTICA EDUCACIONAL: REPENSANDO SUA CONSOLIDAÇÃO NA CONTEMPORANEIDADE
}

\author{
Francisco Wallison Dias Costa1; Wilder Kleber Fernandes de Santana ${ }^{2}$; Eva Bessa Soares ${ }^{3}$; \\ Vicente de Paulo dos Anjos Landim4; Elder Cardoso Fernandes Silva5; Richardson Lemos de

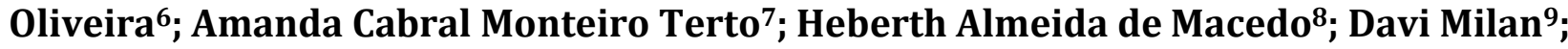 \\ Alessandra Ferreira dos Santos ${ }^{10}$ and Reginaldo Nunes de Araújo Júnior ${ }^{11}$
}

1-2Universidade Federal da Paraíba (UFPB); ${ }^{3}$ Universidade Federal de Ouro Preto (UFOP); ${ }^{4}$ Centro Universitário Inta (UNINTA); ${ }^{5}$ Universidade Católica de Petrópolis (UCP); ${ }^{6}$ Universidade Nacional de La Plata (UNLP); 7Universidade Mogi das Cruzes; ${ }^{8}$ Faculdade Israelita de Ciências da Saúde Albert Einstein; ${ }^{9}$ Faculdade da Alta Paulista; 10Universidade Lá Salle; 11Faculdades Integradas Pitágoras de Montes Claros

\section{ARTICLE INFO}

\section{Article History:}

Received $06^{\text {th }}$ February, 2021

Received in revised form

$16^{\text {th }}$ March, 2021

Accepted $28^{\text {th }}$ April, 2021

Published online $22^{\text {th }}$ May, 2021

Key Words:

Opportunity cost; Storage; Fuzzy logic;

Spare parts; Accounting.

*Corresponding author:

Francisco Wallison Dias Costa,

\begin{abstract}
Refletir sobre a docência em diálogos com a gestão democrática educacionalexige dos pesquisadores a ideia de participatividade, na medida em que deve ser arquitetado um trabalho coletivo. Na sociedade pós-moderna, aquilo que se apresenta como democrático está previsto na Constituição Federal de 1988 (CF) na Lei de Diretrizes e Bases da Educação (Lei no 9.394/96). O objetivo de nosso trabalho consiste em problematizar a consolidação da gestão democrática educacional e consequentemente da Docência na contemporaneidade, ou seja, até que ponto essa práxis é de fato consolidada? No que tange à interrelação com a docência, os resultados da nossa pesquisa apontaram que se torna mister obter uma participação ativa do docente e de todos os que compõem a comunidade escolar de forma a garantir a qualidade nos processos de ensino e aprendizagem.
\end{abstract}

Copyright (C) 2021, Francisco Wallison Dias Costa et al. This is an open access article distributed under the Creative Commons Attribution License, which permits unrestricted use, distribution, and reproduction in any medium, provided the original work is properly cited.

Citation: Francisco Wallison Dias Costa; Wilder Kleber Fernandes de Santana; Eva Bessa Soares; Vicente Paulo dos Anjos Landim; Elder Cardoso Fernandes Silva; Richardson Lemos de Oliveira; Amanda Cabral Monteiro Terto; Heberth Almeida de Macedo; Davi Milan; Alessandra Ferreira dos Santos and Reginaldo Nunes de Araújo Júnior, 2021. "Docência e gestão democrática educacional: repensando sua consolidação na contemporaneidade", International Journal of Development Research, 11, (05), 47073-47076.

\section{INTRODUÇÃO}

Quando nos remetemosàDocência e refletimos sobre sua interrelação à gestão democrática educacional, de imediato convocamos a ideia de participatividade (BAKHTIN, 2010), oriunda de um trabalho coletivo. Na sociedade pós-moderna (BAUMAN, 1998; 2001) o que se apresenta como democrática parte da tomada de decisões e ações, na medida em que apráxis democrática se faz presente.No entanto, ainda somos confrontados comquestionamentos e reflexões diante da realidade de diversas instituições escolares, se realmente a gestão democrática educacional constitui uma "nova escola". Assim, se faz importante entendercomo se estabeleceram diálogos efetivos entre a docência e a gestão democrática educacional, ou seja, como se efetivam a docência e a gestão escolar democrática e nas escolas?

Para esse propósito recorremos à promulgação da Constituição Federal de 1988 (CF) e à criação da Lei de Diretrizes e Bases da Educação (Lei no 9.394/96) como dois dos grandes marcos da legislação educacional, e fortemente ligadasàs políticas educacionais democráticas, por meio das quaisa educação ganhou maior visibilidade e uma olhar pautado na gestão democrática. Estudos como os de Gracindo e Wittmann (2001), Pereira e Andrade (2005), e Souza (2006), que trazem revisões de literatura sobre o tema gestão escolar revelam uma crescente preocupação nas produções nacionais, desde o final da década de 1990, com a identidade do administrador escolar, a reconstrução de seu perfil e as novas exigências da função. Do mesmo modo, estudos sobre Docência são protagonizados por estudiosos como Bortoni-Ricardo (2008), Fior\& Martins (2018), Murphy, 2020. Libâneo (2007) se refere à utilização do termo gestão escolar quando se associa à escola, e trabalha com uma concepção sócio crítica de gestão escolar, o que agrega consigo a questão da Docência. Nessa concepção, a gestão escolar também é engendrada como um sistema que agrega pessoas, "considerando o caráter intencional de suas ações e as interações sociais que estabelecem entre si e com o contexto sócio-político, nas formas democráticas de tomada de decisões" (LIBÂNEO, 2007, p. 324). O artigo nº 206 da 
CF/88 e o artigo $3^{\circ}$ da Lei $n^{\circ}$ 9.394/96 garantem que a Docência no ensino público deve conter os preceitos da gestão democrática, haja vista que a própria legislação brasileira em sua Carta Magna já á garante, presumindo que as relações de poder dentro das instituições de ensino devam gerar integração, cooperação e participação, e, para isso, as propostas precisam ser construídas e reconstruídas pelas próprias pessoas envolvidas com a escolarização.Assim, a princípio, faz-se importante entender a forma da Lei que institui a Gestão democrática educacional.

A importância da educação e do seu impacto na qualidade de vida da população é tão evidente que há muitas outras legislações, nacionais e internacionais, além das já citadas, que discutem o direito legítimo à educação. Como exemplos, podemse citar dois artigos do Estatuto da Criança e do Adolescente (ECA), Lei no 8.069, de 13 de julho de 1990 e um artigo na Carta Internacional dos Direitos Humanos, também intitulada Declaração Universal dos Direitos do Homem, adotada e proclamada pela Assembleia Geral das Nações Unidas (ONU) na sua Resolução 217A (III) de 10 de dezembro de 1948 (BRASIL/MEC, 2006, p. 57).

Estes princípios legais estão focados na necessidade de ofertar uma educação que se volte para o desenvolvimento do indivíduo enquanto cidadão crítico e reflexivo sobre o seu meio, a partir de um ambiente escolar democrático e adaptado a sua realidade. O objetivo de nosso trabalho consiste em problematizar a consolidação da Gestão Democrática Educacional e da Docência na contemporaneidade, ou seja, até que ponto essa práxis é de fato consolidada?No que tange àinterrelação com a Docência, torna-se mister obter uma participação ativa do docente e de todos os que compõem a comunidade escolar de forma a garantir a qualidade nos processos de ensino e aprendizagem, observando-se as dinâmicas e as especificidades que se fazem presentes no ambiente escolar, garantindo a articulação das diretrizes e políticas educacionais públicas e por consequência, a implementação em sua totalidade.

\section{Gestão Democrática da Educação, Docência e a Legislação}

A Gestão democrática da educação se faz presente na Constituição Federal de 1988 (CF/88), na Lei de Diretrizes e Bases da Educação (LDB/96) e no Projeto de Lei do Plano Nacional de Educação que está em apreciação nas Casas Legislativas (PNE 2011-2020) que viabilizam os princípios, diretrizes, funcionamento, implantação e organização da Gestão democrática educacional, considerando que a Constituição Federal foi promulgada se solidifica como marco da consolidação da democracia do Brasil. Esta constitui-se, portanto, como garantia de direitos estabelecida após o período em que esteve em vigência o Governo Militar.ACarta Magna é conhecida, também, como Constituição Cidadã.Desse modo, no que tange à Educação,no Capítulo III, Seção I, em seu artigo 206, inciso VI, consagra-se a gestão democrática do ensino público, no qual pressupõe os princípios da educação de cada cidadão. Quanto à docência, de acordo com o inciso VIII do artigo $3^{\circ}$ da Lei de Diretrizes e Bases de 1996, infere-se que "O ensino será ministrado com base nos seguintes princípios: (...) VIII - gestão democrática do ensino público, na forma desta Lei e da legislação dos sistemas de ensino", corroborando com o que está na Constituição Federal de 1988. Ainda na LDBo artigo 14, a gestão democrática do ensino público da Educação Básica:

Art. 14. Os sistemas de ensino definirão as normas da gestão democrática do ensino público na educação básica, de acordo com as suas peculiaridades e conforme os seguintes princípios:

I - participação dos profissionais da educação na elaboração do projeto pedagógico da escola;

II - Participação das comunidades escolar e local em conselhos escolares ou equivalentes (BRASIL, 1996).

Estabelece-se, assim, a participação da democratização docente dentro do contexto educacional tanto da comunidade escolar quanto dos conselhos e equivalentes que possibilitam o trabalho coletivo em conformidade com as necessidades da comunidade escolar. $\mathrm{O}$ artigo
15 possibilita o encaminhamento dos processos de autonomia viáveis ao processo. Consta no Art. 15 que "Os sistemas de ensino assegurarão às unidades escolares públicas de educação básica que os integram progressivos graus de autonomia pedagógica e administrativa e de gestão financeira, observadas as normas gerais de direito financeiro público". Quem seriam, então, os docentes que protagonizam o ensino, e ao mesmo tempo integram o processo gestor escolar?

São profissionais das diferentes áreas do conhecimento, mas que, por alguma razão, acabam chegando a ser professor do ensino superior. Muitos docentes do ensino superior, ao serem questionados pela profissão que exercem, identificam-se primeiramente como sendo o médico, o dentista, o advogado, o contador, o físico, o engenheiro, o jornalista, o radialista, seguido, às vezes, pela identificação de professor universitário, porque responder apenas professor pode dar margem a uma identidade socialmente inferior (MEDEIROS, 2005, p. 73).

Essa multiplicidade de diversas esferas do conhecimento nos faz refletir sobre o fato de que a escola, gestão e comunidade escola, tem por sua vez que estabelecer e garantir a autonomia como garantia da gestão democrática. Para assim assegurar tal processo bem como como sua aplicabilidade, utilizamos do artigo $1^{\circ}$ do PNE (2011-2020), que trata da aprovação da Lei e indica o cumprimento do artigo 214 da Lei Maior:

Art. 214. A lei estabelecerá o plano nacional de educação, de duração decenal, com o objetivo de articular o sistema nacional de educação em regime de colaboração e definir diretrizes, objetivos, metas e estratégias de implementação para assegurar a manutenção e desenvolvimento do ensino em seus diversos níveis, etapas e modalidades por meio de ações integradas dos poderes públicos das diferentes esferas federativas que conduzam a:

Por meio da instituição desse Artigo, garante-se, dentro do inciso X do artigo $2^{\circ}$ do referidoPlano Nacional de Educação (2011-2020), a "difusão dos princípios da equidade, do respeito à diversidade e a gestão democrática da educação", nas estratégias a serem implementadas quanto a gestão democrática visando a realização de 02 (duas) das 20 (vinte) metas do PNE. Na estratégia 7.1 não aparece o termo gestão democrática da educação, mas apenas gestão educacional, a gestão é compreendida como operacionalizada para gerir e organizar, buscando intermediar os recursos e sua aplicabilidade. Já na estratégia 7.8 da participação“e a efetiva gestão democrática da escola" (PNE 2011-2020).

7.8) Apoiar técnica e financeiramente a gestão escolar mediante transferência direta de recursos financeiros à escola, com vistas à ampliação da participação da comunidade escolar no planejamento e na aplicação dos recursos e o desenvolvimento da gestão democrática efetiva

Meta 19: Garantir, mediante lei específica aprovada no âmbito dos Estados, do Distrito Federal e dos Municípios, a nomeação comissionada de diretores de escola vinculada a critérios técnicos de mérito e desempenho e à participação da comunidade escolar

É imprescindível entender as bases ativas da função do docente como um dos elementos-chave para funcionamento do processo gestor.Assim, compreende-se que a "7) Gestão Democrática: referente aos sistemas de ensino e das instituições educativas, constitui uma das dimensões fundamentais que possibilitam o acesso à educação de qualidade como direito universal".Agestão democrática da escola ${ }^{1}$ é considerada condição de possibilidade de uma educação

\footnotetext{
1 A gestão democrática como princípio da educação nacional, sintoniza-se com a luta pela qualidade da educação e as diversas formas e mecanismos de participação encontradas pelas comunidades local e escolar na elaboração de planos de desenvolvimento educacional e projetos político-pedagógicos, ao mesmo tempo em que objetiva contribuir para a formação de cidadãos/ãs
} 
de qualidade enquanto direito que deve ser garantido a todos. A gestão democrática deve contribuir para o fomento de um projeto político pedagógico participativo cujos fundamentos coadunam com a sociedade democrática e com a prática cidadã no interior da instituição escolar.

Problematizando a consolidação da Docência e da Gestão Democrática: A gestão democrática ${ }^{2}$ é definida para Araújo (2009, p. 20) como "[...] forma de possibilitar que todos os seres envolvidos na instituição possam exercer com maior assertividade sua cidadania, se relacionar melhor e alcançar a liberdade de expressão. No caso dos docentes que protagonizam o ensino, "os envolvidos incorporam mais conhecimentos, sejam eles formais ou informais, tornando-os mais responsáveis, autônomos e criativos" (ARAÚJO, 2009, p. 20). Conforme Lück (2006) a educação na sociedade do conhecimento remete ao real posicionamento das pessoas como sujeitos ativos, conscientes e responsáveis pelos processos sociais e das instituições em que estão inseridos. De igual modo, é preciso compreender que as ações não são neutras ou isoladas, nenhuma delas será capaz de, por si só, promover avanços consistentes e duradouros na escola. Diante disso denota-se a importância do papel do gestor para a construção a mobilização das pessoas inseridas neste contexto de forma articulada e coletiva, posicionando-se efetivamente na escola com o compromisso coletivo para a transformação da realidade. É importante compreendermos que a gestão democrática educacional ${ }^{3}$ se consolida diante de ações pautadas na coletividade, no entanto a realidade na forma da lei, se contrapõe ao dinamismo dos espaços e sujeitos dentro do processo, no qual ainda é notório a não participação dos sujeitos a deliberação e no comprometimento das ações e espaços democráticos oferecidos e viabilizados através da legislação educacional. Como exemplo, cito a pesquisa realizada na monografia intitulada "O papel do gestor ${ }^{4}$ numa perspectiva democrática: um estudo na escola Municipal de Ensino Infantil e Fundamental Antônia fragoso de Araújo, no Município de Santa Maria do Pará" (COSTA, 2012).

Em linhas paralelas, compete ao docente aprimorar cada vez mais as suas atitudes profissionais, buscando por meio da reflexão de

críticos/as e compromissados/as com a transformação social. Nesse sentido, deve contribuir para a consolidação de política direcionada a um projeto políticopedagógico participativo, que tenha como fundamento: a autonomia, a qualidade social, a gestão democrática e participativa e a diversidade cultural, étnico-racial, de gênero, do campo (PNE 2011-2020).

${ }^{2}$ No que se refere à gestão escolar democrática e quanto aos aspectos que propiciam um ambiente escolar mais equitativo, apresentam a figura do gestor escolar como um mediador da maioria dos debates em grupo dentro do ambiente supracitado. Condicionalmente os mecanismos de participação como Associação de pais e mestres, construção do Projeto Político Pedagógico, conselho de classe e equivalentes devem ser parte fundamental deste processo, deliberando a tomada de decisões de forma coletiva e participativa, para isso, também devemos ter um gestor bem articulado com a sua equipe, o que resulta numa prática consistente da gestão democrática como um todo. Na escola a gestão democrática, o profissional responsável por esse processo também vem participando mais e se adaptando as necessidades e as novas demandas, e, portanto, com novos desafios.

3 O desafio apontado na atualidade quando se assume o cargo de Gestor Escolar está praticamente baseado nas múltiplas funções que serão desempenhadas ao longo do trabalho. A articulação entre todos os ambientes, além de garantir que os profissionais consigam exercer as suas funções de maneira saudável dentro de um ambiente escolar propício para o mesmo, contudo participativo. Nesse sentido, Paro (1997) nos alerta para este relevante desafio enfrentado pelo gestor escolar, uma vez que, embora este seja outorgado pretensamente como autoridade máxima na escola, continua exercendo ainda o papel preposto pelos órgãos centrais. O que confirma mais uma vez que essa decisão só foi mais uma estratégia utilizada para suprimir do Estado à culpa pelo insucesso dos processos educativos.

${ }^{4}$ Como premissa, o gestor precisa ter experiência e saberes referentes aos processos de ensino-aprendizagem, uma vez que a finalidade da gestão escolar é subsidiar meios para facilitar à atividade do educador em cumprir sua função na formação dos alunos e cidadãos conscientes, autônomos, participativos e atuantes na sociedade. Segundo Ferreira \& Aguiar (2000, p. 197): “Gestão se constitui de princípios e práticas decorrente que afirmam ou desafirmam os princípios que as geram. Estes princípios, entretanto não são intrínsecos à gestão como a concebia a administração clássica, mas são princípios sociais, visto que a gestão da educação se destina à promoção humana". suas ações a superação das práticas centralizadoras e valorizando as experiências dos demais profissionais, refletindo-as e reelaborando-as no coletivo. Administrar se caracteriza como um desafio, pois "não se trata apenas de desenvolver a prática reflexiva, mas de compreender a base das relações sociais e de trabalho em que ela se realiza e a que interesses ela poderá servir" (LIMA, 2005, p. 41). A escola é o local possível de proporcionar uma educação de qualidade a todos, é neste lugar, onde se forma indivíduos críticos, que buscam exercer sua cidadania, com perspectivas de cumprir seu papel frente à sociedade em que vive. A tarefa pedagógica e administrativa, não é uma tarefa simples, requer raciocino, observação, replanejamento, busca de novos caminhos para os erros e fracassos. Segundo Gadotti (2004)

É preciso entender o que é democratização para que se possa efetivá-la A participação possibilita à população um aprofundamento do seu grau de organização. [...] ela contribui para a democratização das relações de poder no seu interior e, consequente, para a melhoria da qualidade do ensino. (GADOTTI, 2004. p. 16).

A democracia dentro da escola estabelece que o gestor tenha a consciência de que ele é um articulador de ideias de modo que o grupo de trabalho tenha liberdade para dar opiniões sobre as decisões. $\mathrm{O}$ gestor é o mediador de decisões, assim como professor medeia o aprendizado do aluno, facilitando sua compreensão, isso significa que o gestor também é um mediador nas ações que envolvem atividades no contexto educacional.Para se criar uma escola democrática é preciso ter em mente que todos os membros possuem uma responsabilidade social sobre o seu papel frente à aprendizagem e formação do aluno, para se construir uma gestão democrática na escola é preciso ter uma liderança compartilhada no sentido de que o gestor esteja aberto a opiniões sem medo de perder sua autoridade e poder dentro desse contexto, à medida que todos atuem na escola. É fundamental a compreensão que na gestão democrática todos podem contribuir para o bom funcionamento da instituição educacional, tendo em vista um planejamento coletivo que tenha como objetivo final a aprendizagem significativa do educando, o diálogo, a convivência e a organização pedagógica e administrativa da escola.

\section{Considerações Finais}

Por meio desse estudo sobre a Docência e sua interrelação à gestão democrática educacional,é possível constatar que a estrutura organizacional das escolas deve ter como princípio o trabalho em conjunto entre todos os sujeitos que fazem parte do grupo escolar, agem em prol dos objetivos da educação relacionada à sociedade $\mathrm{e}$ formação dos alunos. O gestor escolar tem papel muito importante no centro das organizações escolares, pois ele deve ser considerado como o mediador de todas as ações efetuadas pelos componentes da escola. A instituição escolar não deve ser uma instituição que age de forma isolada, mas estabelece relações com toda a sociedade. Sendo o gestor o representante da instituição, ele necessita de conhecimentos administrativos e pedagógicos. As escolas precisam estar em consonância com as necessidades da sociedade em constante transformação, com o ideal de transcender com esta educação atual que atende apenas as necessidades e interesses do capitalismo. Romper com a forma sistêmica de funcionamento do sistema escolar não acontece de modo radical, pois a ruptura dessa lógica social se faz por meio da organização da sociedade civil que tenha a utopia de construir uma sociedade superior, mais justa e igualitária. Para conseguir o engajamento e mobilização nesta luta, precisamos do fortalecimento de um coletivo que se articule em busca deste ideal, portanto criar novos comportamentos que fortaleçam o coletivo é um desafio que se impõe a todos nós que estamos comprometidos com a educação. A consolidação de um ambiente escolar interativo por meio da gestão participativa deve ser mediada por valores e eixos da gestão democrática - família, Estado, sociedade, comunidade desmembrados em norteadores como a ética, a valorização profissional, a flexibilidade, o compromisso e a responsabilidade, dentre outros não menos importantes. $\mathrm{O}$ desempenho do papel de gestor escolar requer comprometimento, liderança, capacidade 
administrativa, sobretudo, ações permeadas pela liberdade, autonomia, responsabilidade e atitudes democráticas.

\section{REFERÊNCIAS}

ARAÚJO, M. C. M. Gestão escolar. Curitiba: IESDE, 2009.

BAUMAN, Zygmunt. O mal-estar da pós-modernidade. Rio de Janeiro: Zahar, 1998.

BAUMAN, Zygmunt. Modernidade Líquida. Rio de Janeiro: Zahar, 2001.

BORTONI-RICARDO, Stella Maris. O professor pesquisador: introdução à pesquisa qualitativa. São Paulo: Parábola Editorial, 2008.

BRASIL. Constituição da República Federativa do Brasil. Brasília, DF: Senado Federal: Centro Gráfico, 1988. Disponível em: http://www.planalto.gov.br/ccivil_03/constituicao/constituicao.ht m. Acesso em 04 de julho de 2020.

Lei de Diretrizes e Bases da Educação, LDB 9.394. Brasília, DF: Palácio do Planalto: 1996. Disponível em: http://www.planalto.gov.br/ccivil_03/Leis/L9394.htm. Acesso em 04 de julho de 2020.

Projeto de Lei PNE - 2011-2020. Portal Planalto Presidência da República. Disponível em: . Acesso em: 04 jul. 2020.

, Ministério da Educação. Gestão democrática nos sistemas e na escola. Brasília: Universidade de Brasília, 2007.

Plano nacional de educação: lei federal n. 13.005 , de 25 de junho de 2014.

COSTA, Francisco Wallison Dias. O Papel do gestor escolar numa perspectiva democrática: um estudo na Escola Municipal de Ensino Infantil e Fundamental "Antônia Fragoso de Araújo", no Município de Santa Maria do Pará. Monografia de graduação. Universidade do Estado do Pará, 2012.

FERREIRA, E. B. A organização da instituição de ensino após a LDB/1996 e as condições do trabalho pedagógico. Disponível em www.coordenacaoescolagestores.mec.gov.br/ufsc Acesso em 06 julho 2020.
FIOR, Camila Alves; MARTINS, Maria José. A docência universitária no contexto de pandemia e o ingresso no ensino superior. Revista Docência do Ensino Superior, v. 10, p. 1-20, 2020.

GADOTTI, M; ROMÃO, J. E. Autonomia da Escola. 6. ed. São Paulo: Cortez, (Guia da escola cidadã; v.1), 2004.

Escola cidadã: a hora da sociedade. In: MEC. Salto para o futuro: construindo a escola cidadã, projeto político-pedagógico. Brasília: MEC, 1998, p. 22-29.

GRACINDO, R. V.; WITTMANN, L. C. (Org.). O estado da arte em política e administração da educação no Brasil: 1991-1997. Campinas: Autores Associados, 2001. 272p.

LIBÂNEO, J. C. A organização e a gestão da escola: teoria e prática. Goiânia: Alternativa, 2007.

LUCK, H. Gestão escolar e formação de gestores. Em aberto, Brasília: Inep, v. 17, n. 72, 2000, p. 11-34. Gestão educacional: uma questão paradigmática. Petrópolis: Vozes, 2007.

Concepções e processos democráticos de gestão educacional. 2 ed. Petrópolis: Vozes, 2007.

Dimensões de gestão escolar e suas competências. Curitiba: Editora Positivo, 2009.

LUCKESI, C. C. Gestão democrática da escola, ética e sala de aula. ABC Education, n. 64. São Paulo: Criarp, 2007.

MURPHY, Michael P.A. COVID-19 andemergencyeLearning: consequencesofthesecuritizationofhighereducation for postpandemicpedagogy. Contemporary Security Policy, 2020.

PARO, V. H. Eleição de Diretores: A escola pública experimenta a democracia. Campinas: Papirus, 1996

PEREIRA, G. R. de M.; ANDRADE, M. da C. L. de. A construção da administração da educação na RBAE (1983-1996). Educação \& Sociedade, Campinas, v. 26, n. 93, p. 1393-1411, set./dez. 2005.

SILVA, E. P. da. A importância do gestor educacional na instituição escolar. Revista Conteúdo, Capivari, v. 1, n. 2, p. 67- 83. jul./dez. 2009.

SOUZA, A. R. de. Os caminhos da produção científica sobre Gestão Escolar no Brasil. RBPAE, São Paulo, v. 22, n. 1, p. 13-39, 2006. 